\title{
Genetic Analysis and Genealogy of Ancient Bone Samples
}

\author{
Maryam Ramezani ${ }^{1}$, Mahmood Tavallai', Peyman Zargari', Hasan Bahmani', Sajad Habibi', Mostafa Khafaei', Zeinab \\ Salehi', Raheleh Tabkhi', Somaieh Chavoshi', Atefeh Ghotbi', Fatemeh Ghotbi', Ali Mohammadi'*
}

${ }^{1}$ Human Genetics Research Center, Baqiyatallah University of Medical Sciences Tehran, Iran

Corresponding Author: Ali Mohammadi, Human Genetics Research Center, Baqiyatallah University of Medical Sciences Tehran, Iran. Tell: +98-2186034956, Email: sepehre3293@Gmail.com

Received July 3, 2018; Accepted September 4, 2018; Online Published September 30, 2018

\begin{abstract}
The analysis of ancient DNA (aDNA) can inspire both the public and the scientific community. Knowing about ancient human genomes and comparing them with those of modern humans can give us a new perspective on evolution and the migration of humans over time. aDNA is DNA isolated from ancient specimens. It can also be loosely described as any DNA recovered from biological samples that have not been preserved specifically for later DNA analysis. Examples include DNA recovered from archaeological and historical skeletal material, mummified tissues, archival collections of non-frozen medical specimens, preserved plant remains, ice and permafrost cores, Holocene plankton in marine and lake sediments, and so on. Due to considerable anthropological, archaeological, and public interest, human remains receive ample attention from the DNA community. Genetic genealogy is the use of DNA testing in combination with traditional genealogical methods to infer relationships between individuals and to find ancestors. Genetic genealogy involves the use of genealogical DNA testing to determine the level and type of genetic relationship between individuals. DNA markers such as autosomal single nucleotide polymorphisms (SNPs), Y SNPs, and mitochondrial DNA (mtDNA) SNPs are used. By analyzing the sequence of mtDNA and the Y-chromosome, the path of human migration throughout history and the common ancestor of humans can be identified. mtDNA analysis is a field of research in genetics and molecular archaeology that is efficient in less than ideal conditions, such as with biologically degraded materials. The mtDNA molecule not only has a high copy number, but it can also be extracted from very decayed biological specimens. Its D-loop region is polymorphic, consisting of two hypervariable regions (HVI and HVII) with a large variety in different human populations. The analysis of such mtDNA regions using ancient excavated human bones will determine the genetic composition of human mtDNA known as haplogroups and can be used to identify ancient ethnic groups, trace descendants of ancestors, and follow man's migration trails.
\end{abstract}

Keywords: Ancient DNA, Genealogy, DNA Markers, mtDNA, SNPs, Y Chromosome

Citation: Ramezani M, Tavallai M, Zargari P, et al. Genetic analysis and genealogy of ancient bone samples. Int J Med Rev. 2018;5(3):130-134. doi:10.29252/IJMR-050306.

\section{Introduction}

Genes form the fundamental identity of all living beings and, along with environmental influences, determine all their traits. Hence, genetics has been widely used in areas such as medicine, pharmacy, animal husbandry, agriculture, anthropology, and identification. Genetics can be used for kinship analysis, identification of individuals, and determination of the genetic lineage and genealogy of a human. ${ }^{1-3}$

Genetic maps are a key component and essential tool needed in molecular anthropology plans in the future. Perhaps one of the most important applications of DNA markers is the preparation of genetic maps that can determine the gene and chromosome position of the genes determining desired traits (sequencing and spacing of genes and markers on chromosomes)..$^{3-5}$ Overall, any trait that varies from one person to another is caused by a difference in DNA chromosomal sequences that is passed down to children. Even traits that appear differently under the influence of environmental conditions (inter-individual differences under the same environmental conditions) reflect differences in DNA sequences. These differences can be employed as genetic markers.

Specific similarities in genetic structures provide the ability to identify haplogroups of different groups of people in the phylogenetic tree or their geographic origin, estimate common ancestors, and identify when the genes entered the population. In terms of paternal genetics (Y-chromosome) or maternal genetics (mitochondrial DNA), innovation of genetic mapping is important in tracing migratory patterns, human habitats, the formation of contemporary populations, and their progress over time..$^{5-10}$

\section{Mitochondrial DNA Markers}

Mitochondrial DNA (mtDNA) consists of 37 genes that code 13 proteins, 22 tRNAs, and 2 rRNAs. Its 28 genes are coded by the heavy strand and 9 other genes by the light strand.

Copyright $\odot 2018$ The Author(s). This is an open-access article distributed under the terms of the Creative Commons Attribution License (http:// creativecommons.org/licenses/by/4.0), which permits unrestricted use, distribution, and reproduction in any medium, provided the original work is properly cited. 
Thirteen proteins produced are associated with the oxidative phosphorylation system in the mitochondria. Traits that have made mtDNA known as a genetic marker in genealogy studies include the following:

1. Each cell contains several thousand copies of the mitochondrial genome, but only one copy of the nuclear genome is present in the cell;

2. Mitochondria have only a maternal inheritance, through which the maternal ancestor can thus be investigated;

3. The mutation rate in the mitochondrial genome is high (approximately 100 times more than the nuclear genome). The recombination rate in $\mathrm{mtDNA}$ is lower than that of the nuclear genome $\mathrm{e}^{10-15}$ (Figure 1).

\section{Y-Chromosome Markers}

Y-chromosome polymorphism is also used to study human migration in order to provide information about the human origin (this time emphasizing the paternal role). ${ }^{10-12}$ Both short tandem repeats (microsatellites) and SNPs are used to assign individuals to haplogroups in a similar way to mtDNA. Many previous demographic studies are a combination of mtDNA analysis and Y-chromosome diversity, ${ }^{12}$ which provides evidence of the paternal and maternal lineage. In general, the Y-chromosome haplogroups, in contrast to mtDNA, show stronger local and geographic patterns, which is probably due to the fact that the native father (men lived in places where their fathers previously lived) is a trait among many human

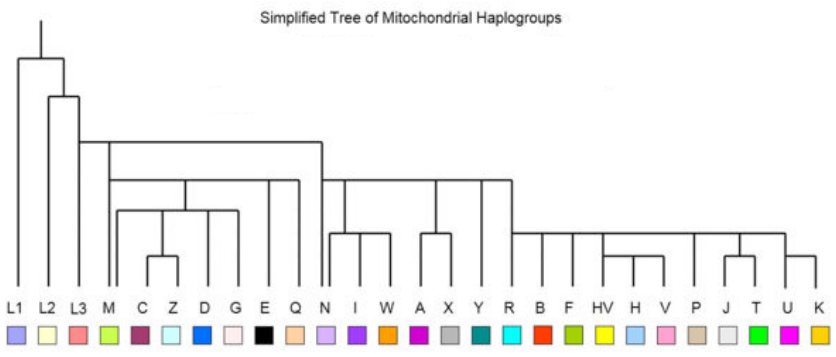

Figure 1. Simplified Tree of mtDNA Haplogroups. (https://www.wikitree. com/wiki/Space:Major_Y-DNA_and_mtDNA_Haplogroups).

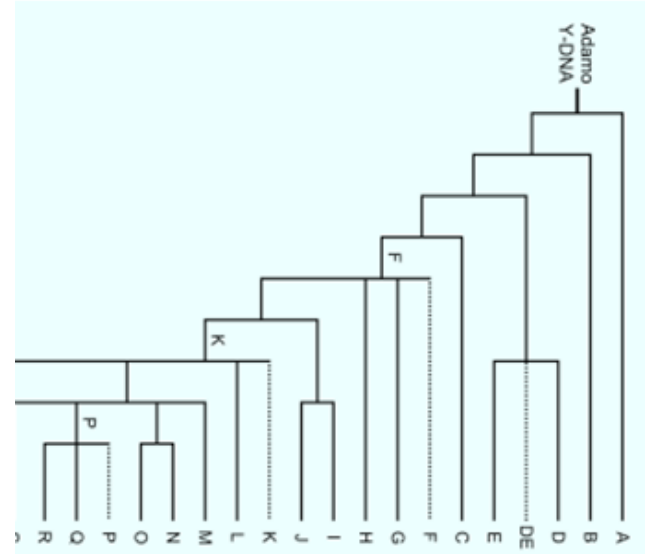

Figure 2. Simplified Tree of Y-Chromosome Haplogroups (https://www. wikitree.com/photo/jpg/Major_Y-DNA_and_mtDNA_Haplogroups-4). cultures (Figure 2). ${ }^{16}$

\section{Archaeogenetics}

Archaeogenetics is a term coined by Colin Renfrew to refer to the use of molecular genetic techniques to study the past life of humans, ${ }^{1}$ which include the following:

1. Analysis of DNA extracted from remains discovered from excavations and archaeological investigations;

2. Analysis of DNA obtained from modern populations (including humans, plant species, and domesticated animal species) to study the past life of humans and achieve a better understanding of the interaction between genetic heritages and Earth's ecosystems;

3. Application of statistical methods developed by molecular geneticists with regard to archaeological data. ${ }^{2}$

\section{Barriers to and Limitations of DNA Extraction and Use}

All components of the human body degrade after death, and DNA is no exception. In many ancient samples, no DNA was detectable, and in cases where DNA was found, it had greatly degraded, with only a little more than 100 nucleotides remaining intact. When some DNA remains in ancient bones, the amount is usually very low, i.e. less than $2 \%$ of the amount found in late bone samples. ${ }^{17-20}$

Contamination is the biggest technical problem while studying ancient DNA (aDNA). Contamination by modern human DNA may be encountered during exploration, occurring in post-exploration phases or in the laboratory. This issue is due to a high presence of modern DNA than ancient DNA. Any contact between skin cells, transpiration, or modern human saliva and ancient specimens poses a serious threat of contamination to the ancient specimens, which means that contamination by modern DNA can give false results. Consequently, instead of aDNA, the modern DNA will generally be identified by polymerase chain reaction (PCR).

Several methods have been identified and introduced for preventing, detecting, and eliminating contamination in samples. An ideal relevant strategy is to prevent contamination of bone samples before they reach the laboratory. One method is to remove the bone surface. ${ }^{20-23}$

\section{Application of Genetic Information}

The first complete sequence of human mtDNA (16569 bp) was obtained in 1981. ${ }^{17}$ This sequence, called the Cambridge Reference Sequence (CRS), was used as a source sequence to study the human mitochondrial genome. ${ }^{18-20}$ In 1999, a modified version of the same modified sequence of the first version was introduced and called the revised Cambridge Reference Sequence (rCRS). ${ }^{23}$

The human mitochondrial genome is composed of a coding region and a non-coding region. The coding region consists of 37 genes, 13 of which code proteins, 22 code tRNA, and 2 code rRNA genes. ${ }^{24,25}$ The non-coding region, also called the control region, has highly variable regions (HVR), which get their names from the large genetic variation seen in these regions in comparison with the coding sequence. ${ }^{26}$ Genetic variation is produced by a process called mutation, which can 
be created by the substation, removal, or addition of bases. ${ }^{23}$

Ancient DNA is often used to determine the racial evolution or the classification of extinct species which was previously investigated through morphology or data from fossils. In order to study the racial evolution, specific regions of mtDNA, such as HVR and cytochrome b, were first used, but the advancement of sequencing techniques allowed for the investigation of all mtDNA sequences. ${ }^{17,18}$

Individuals showing a common ancestor in their evolutionary background are classified in a haplogroup. This term was first introduced in a study on four A, B, C, and D haplogroups based on the RFLP technique. The researchers placed those mtDNA lineages derived from Africa in an $\mathrm{L}$ haplogroup and those created after leaving Africa in the L3 haplotype which consisted of two subgroups of $M$ and N. ${ }^{16-20}$ Previous mtDNA studies showed the geographical distribution patterns of haplogroups worldwide. The large haplogroup $\mathrm{M}$ consists of haplogroups $\mathrm{C}, \mathrm{D}, \mathrm{E}, \mathrm{G}, \mathrm{Q}$, and Z, which are currently found in Asia, Oceania, and America. The large haplogroup $\mathrm{N}$ is divided into two branches; the first branch is $\mathrm{R}$, which is divided into haplogroups $\mathrm{B}, \mathrm{F}, \mathrm{J}$, $\mathrm{P}, \mathrm{T}, \mathrm{R} 0$ (including $\mathrm{H}, \mathrm{HV}$, and $\mathrm{V}$ ) and $\mathrm{UK}$ (including $\mathrm{U}$ and $\mathrm{K})$. The second branch refers to haplogroups other than $\mathrm{R}$, which are characterized by $\mathrm{N}^{*}$ and include subgroups $\mathrm{A}, \mathrm{N} 1$, $\mathrm{O}, \mathrm{S}, \mathrm{X}$, and Y. N1 itself is divided into groups N1a, N1b, and I (Figure 3). ${ }^{27}$

The geographical patterns of haplogroup distribution are used to determine the human migration route throughout history. ${ }^{27}$

\section{Discussion and Conclusion}

Archaeogenetics defines the story of the spread of human beings across the world, from their origin in Africa hundreds of thousands of years ago to the movements of people during the past few decades. This includes everything, including the recent exit of people from Africa when they settled around the world to the development of agriculture in Africa, Asia, Europe, and even Oceana, and dispersed populations. ${ }^{28}$ Archaeogenetics examines the geographical distribution of modern human genetic diversity with the aim of answering questions related to issues of archeology, anthropology, and history. This work is initially carried out by combining phylogenetic inter-lineage relationships with respect to their geographical distributions and variations with respect to the dimension of time using the molecular clock.

The main objective of mtDNA research is to determine maternal genetic estimates; the aim of Y-chromosome research is to provide phylogeographic models to achieve a better understanding of human variations, the male lineage, and the diversity of genomes spread on the available autosomes. ${ }^{28-30}$ The mutated nucleotides of the Y-chromosome are transmitted as a polymorphism through the father to his male child. Single nucleotide polymorphisms (SNPs) are tools for comparing individuals based on the genetic structure of their paternal ancestors.

All of these polymorphisms form a haplotype in one person, and the diversity of haplotypes in different lineages creates the branches of the Y-chromosome phylogenetic genealogy. The main branch of human phylogenetic genealogy is referred to as a haplogroup, and each haplogroup is subdivided into subhaplogroups. The study of molecular anthropology provides precise divisions of these sub-branches and introduces special geographic regions for their initial origins and their current abundance..$^{30-32}$

The geographic location of Iran and its importance in the ancient world is significant in terms of knowing migration patterns. The land of Iran, as an important passage, welcomed populations with distinct languages, religions, and other cultural aspects. However, few studies have been conducted on the genetic diversity of Iranian ethnic groups. ${ }^{32-35}$ Migrations and various events which have been seen on the Iranian plateau and have led to the arrival and receipt of new genes as well as the creation of genetic diversity have turned the gene pool of the Iranian population into an important source of Y-chromosome diversity in the Middle East and Eurasia at different times. Various studies on the paternal gene pool (Y chromosome) of the present population of Iran have indicated the settlement and migrations throughout the Middle East in

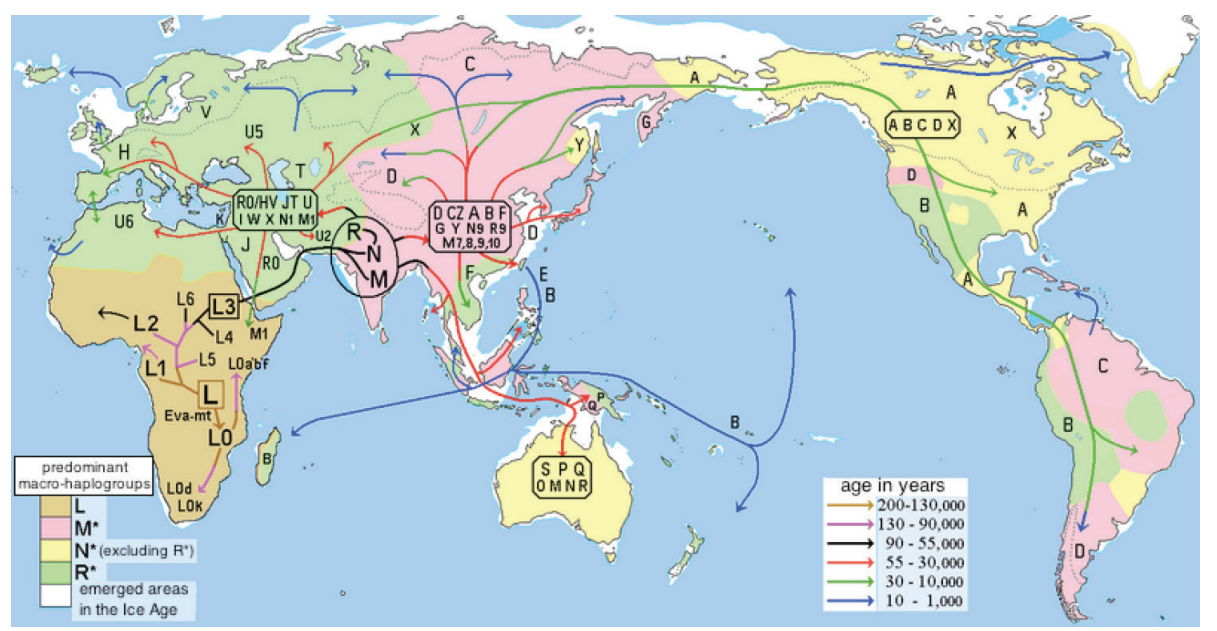

Figure 3. Human migrations based on mitochondrial haplogroups (https://en.wikipedia.org/wiki/File:Human_migrations_and_mitochondrial_ haplogroups.PNG). 
the past, which have formed the current genetic structure of Iranians. ${ }^{35,36}$

Genecology using molecular methods such as DNA fingerprinting is being employed for various purposes around the world. ${ }^{37}$ Molecular markers such as STRs, mtDNA, single SNPs at the Y-chromosome surface, and other chromosomes can be used. The study of mtDNA and Y-chromosome can help trace maternal and paternal ancestors, respectively. Archeological studies also investigate special characteristics such as the existence of a significant relationship between SNPs to place a studied sample in a specific group called a haplogroup. ${ }^{37-40} \mathrm{~A}$ haplogroup is, in fact, a bunch of closely spaced haplotypes that take mutations from their common ancestor. Haplotypes are also a set of SNPs in a nucleotide sequence that are transferred to the next generation. ${ }^{38}$ Since all living organisms have DNA and all DNAs differ among different species as well as individuals belonging to a species, DNA analysis is an essential component of modern archeology based on highly sensitive PCR-based techniques which are used to analyze biological samples. This science is referred to as "archaeogenetics". 40 Thus, in spite of the low amounts of DNA found in ancient bone samples, some information can be obtained about the type, gender, ethnicity of the sample, and migrations throughout history.

\section{Authors' Contributions}

All authors contributed equally to this study.

\section{Conflict of Interest Disclosures}

The authors declare they have no conflicts of interest.

\section{References}

1. Allentoft ME, Sikora M, Sjogren KG, et al. Population genomics of Bronze Age Eurasia. Nature. 2015;522(7555):167-172. doi:10.1038/nature14507.

2. Alonso A, Martin P, Albarran C, et al. Real-time PCR designs to estimate nuclear and mitochondrial DNA copy number in forensic and ancient DNA studies. Forensic Sci Int. 2004;139(2-3):141149. doi:10.1016/j.forsciint.2003.10.008.

3. Costa MD, Pereira JB, Pala M, et al. A substantial prehistoric European ancestry amongst Ashkenazi maternal lineages. Nat Commun. 2013;4:2543. doi:10.1038/ncomms3543.

4. Gamba C, Jones ER, Teasdale MD, et al. Genome flux and stasis in a five millennium transect of European prehistory. Nat Commun. 2014;5:5257. doi:10.1038/ncomms6257.

5. Haber M, Doumet-Serhal C, Scheib C, et al. Continuity and Admixture in the Last Five Millennia of Levantine History from Ancient Canaanite and Present-Day Lebanese Genome Sequences. Am J Hum Genet. 2017;101(2):274-282. doi:10.1016/j. ajhg.2017.06.013.

6. Kilinc GM, Omrak A, Ozer F, et al. The Demographic Development of the First Farmers in Anatolia. Curr Biol. 2016;26(19):2659-2666. doi:10.1016/j.cub.2016.07.057.

7. Lazaridis I, Mittnik A, Patterson N, et al. Genetic origins of the Minoans and Mycenaeans. Nature. 2017;548(7666):214-218. doi:10.1038/nature23310.

8. Margaryan A, Derenko M, Hovhannisyan H, et al. Eight Millennia of Matrilineal Genetic Continuity in the South Caucasus. Curr Biol. 2017;27(13):2023-2028.e2027.doi:10.1016/j.cub.2017.05.087.

9. Mathieson I, Lazaridis I, Rohland N, et al. Genome-wide patterns of selection in 230 ancient Eurasians. Nature. 2015;528(7583):499503. doi:10.1038/nature16152.
10. Mohammadi A, Ghorbani Alvanegh A, Khafaei M, et al. A New and Efficient Method for DNA Extraction from Human Skeletal Remains Usable in DNA Typing. J Appl Biotechnol Rep. 2017;4(2):609-614.

11. Olalde I, Brace S, Allentoft ME, et al. The Beaker phenomenon and the genomic transformation of northwest Europe. Nature. 2018;555(7695):190-196. doi:10.1038/nature25738.

12. Valdiosera C, Gunther T, Vera-Rodriguez JC, et al. Four millennia of Iberian biomolecular prehistory illustrate the impact of prehistoric migrations at the far end of Eurasia. Proc Natl Acad Sci U S A. 2018;115(13):3428-3433. doi:10.1073/pnas.1717762115.

13. Zargari P, Habibi Azarian S, Ahmadi K, Erfanmanesh P, Tavallaie M. New Perspective on Tappeh Hesar. SM J Biol. 2016;2(2):1012.

14. Lazaridis I, Nadel D, Rollefson G, et al. The genetic structure of the world's first farmers. bioRxiv. 2016:059311. doi:10.1101/059311.

15. Alakoc YD, Aka PS, Egin Y, Akar N. Factor $V$ Leiden in an Urartian, dating back to 1000 BC. Clin Appl Thromb Hemost. 2010;16(6):679-683. doi:10.1177/1076029609338045.

16. Pakendorf B, Stoneking M. Mitochondrial DNA and human evolution. Annu Rev Genomics Hum Genet. 2005;6:165-183. doi:10.1146/annurev.genom.6.080604.162249.

17. Nesheva D. Aspects of ancient mitochondrial DNA analysis in different populations for understanding human evolution. Balkan J Med Genet. 2014;17(1):5-14. doi:10.2478/bjmg-2014-0019.

18. Paabo S. Molecular cloning of Ancient Egyptian mummy DNA. Nature. 1985;314(6012):644-645. doi:10.1038/314644a0.

19. Cann RL, Stoneking M, Wilson AC. Mitochondrial DNA and human evolution. Nature. 1987;325(6099):31-36. doi:10.1038/325031a0.

20. Wallace DC, Brown MD, Lott MT. Mitochondrial DNA variation in human evolution and disease. Gene. 1999;238(1):211-230. doi:10.1016/S0378-1119(99)00295-4.

21. Miller NF. Economy and settlement in the Near East: analyses of ancient sites and materials. Pennsylvania: UPenn Museum of Archaeology. 1990:47-61.

22. Schmidt EF. Excavations at Tepe Hissar, Damghan. Philadelphia: University of Pennsylvania Press; 1937. doi:10.1017/ S0003598X00014174.

23. Dyson RH, Howard SM. Tappeh Hesār: reports of the restudy project, 1976. Firenze: Casa editrice Le Lettere; 1989.

24. Oudbashi O, Davami P, Emami SMA. Bronze in archaeology: a review of the archaeometallurgy of bronze in ancient Iran. Intech; 2012:153-172. doi:10.5772/32687.

25. Crawford $\mathrm{MH}$. Anthropological genetics: theory, methods and applications. New York: Cambridge University Press; 2007.

26. Gilbert MT, Bandelt HJ, Hofreiter M, Barnes I. Assessing ancient DNA studies. Trends Ecol Evol. 2005;20(10):541-544. doi:10.1016/j.tree.2005.07.005.

27. van Oven $M$, Kayser M. Updated comprehensive phylogenetic tree of global human mitochondrial DNA variation. Hum Mutat. 2009;30(2):E386-394. doi:10.1002/humu.20921.

28. Rock AW, Dur A, van Oven M, Parson W. Concept for estimating mitochondrial DNA haplogroups using a maximum likelihood approach (EMMA). Forensic Sci Int Genet. 2013;7(6):601-609. doi:10.1016/j.fsigen.2013.07.005.

29. Fan L, Yao YG. An update to MitoTool: using a new scoring system for faster mtDNA haplogroup determination. Mitochondrion. 2013;13(4):360-363. doi:10.1016/j.mito.2013.04.011.

30. Lott MT, Leipzig JN, Derbeneva O, et al. mtDNA Variation and Analysis Using Mitomap and Mitomaster. Curr Protoc Bioinformatics. 2013;44:1.23.21-26. doi:10.1002/0471250953. bi0123s44.

31. Stoneking $M$, Krause J. Learning about human population history from ancient and modern genomes. Nat Rev Genet. 2011;12(9):603-614. doi:10.1038/nrg3029.

32. Hofreiter M, Serre D, Poinar HN, Kuch M, Paabo S. Ancient DNA. Nat Rev Genet. 2001;2(5):353-359. doi:10.1038/35072071.

33. James HA, Petraglia M. Modern human origins and the evolution of behavior in the later Pleistocene record of South Asia. Curr 
Anthropol. 2005;46(S5):S3-S27. doi:10.1086/444365.

34. Petraglia MD, Haslam M, Fuller DQ, Boivin N, Clarkson C. Out of Africa: new hypotheses and evidence for the dispersal of Homo sapiens along the Indian Ocean rim. Ann Hum Biol. 2010;37(3):288-311. doi:10.3109/03014461003639249.

35. Achilli A, Rengo C, Magri C, et al. The molecular dissection of mtDNA haplogroup $\mathrm{H}$ confirms that the Franco-Cantabrian glacial refuge was a major source for the European gene pool. Am J Hum Genet. 2004;75(5):910-918. doi:10.1086/425590.

36. Pereira $L$, Richards $M$, Goios $A$, et al. High-resolution mtDNA evidence for the late-glacial resettlement of Europe from an Iberian refugium. Genome Res. 2005;15(1):19-24. doi:10.1101/ gr.3182305.

37. Non A. Analyses of genetic data within an interdisciplinary framework to investigate recent human evolutionary history and complex. University of Florida; 2010:80.

38. Loogvali EL, Roostalu U, Malyarchuk BA, et al. Disuniting uniformity: a pied cladistic canvas of mtDNA haplogroup $\mathrm{H}$ in Eurasia. Mol Biol Evol. 2004;21(11):2012-2021. doi:10.1093/ molbev/msh209.

39. Metspalu M, KivisildT, Metspalu E, et al. Most of the extant mtDNA boundaries in south and southwest Asia were likely shaped during the initial settlement of Eurasia by anatomically modern humans. BMC Genet. 2004;5:26. doi:10.1186/1471-2156-5-26.

40. Aali A, Abar A, Boenke N, et al. The archaeology of the salt miners. Bochum: Deutsches Bergbau-Museum Bochum; 2014. 